Journal of Engineering and Applied Sciences 14 (17): 6419-6424, 2019

ISSN: 1816-949X

(C) Medwell Journals, 2019

\title{
Finite Element Simulation of Continuous FRP Reinforced Concrete Beams
}

\author{
Qusay W. Ahmed, Ali Laftah Abbas and Hafeth I. Naji \\ College of Engineering, University of Diyala, Baqabah, Iraq \\ qusaywahmed20@gmail.com
}

\begin{abstract}
At present the choice of Fiber Reinforced Polymer (FRP) is the best solution to strengthen and rehabilitate engineering structures. The employ of reinforcement technique with FRP offers many benefits to retrofit and repair many construction structures and bridges. The numerical study of the present study aims to scrutinize the nonlinear behavior of beams provided by FRP bars. An numerical three dimensional model is achieved using ANSYS (Version 12.0) Software. This includes: load-mid span deflection behavior, ultimate load and failure modes for samples. The analysis depends on nonlinearity and geometrical of material is adopted. A 3-D sample was created and analyzed for research and study of general behavior of this type of beams provided by carbon polymeric fiber rods. The model presented in this research can be used to represent the practical fiber rods provided in continuous beams. The numerical experimentations using the program was focused on the behavior of the deflection and the maximum loads and showed reliable results and are very consistent with the results of the experimental data.
\end{abstract}

Key words: Fiber reinforced polymer rods, FEA, ANSYS Software, continuous concrete beam, reliable results, nonlinearity

\section{INTRODUCTION}

The use of FRP as a compound material in engineering structures has appeared from a few years ago in the repair and rehabilitation of concrete elements. The high cost of this substance may be the main reason for the reluctance to use it. FRP has many characteristics that distinguish it from ordinary steel, high strength, hardness and light weight, thus, the economic cost will be reduced. This kind is preferred for use in electrical and magnetic branches where it is used as an appropriate substitute for conventional steel reinforced rods (Hollaway, 2011).

Continuous beams are structures that are consistently indeterminate and may be exposed to strong weathering agents and solubility salts. Consequently, FRP is used as an appropriate substitute for conventional steel bars to resist the erosion. The presence of FRP rods in continuous beams will be delivered to redistribute the moment between critical zones, therefore, the behavior of beam will be ductile and give alert before collapse (El-Mogy et al., 2011).

Many studies deal with the behavior of FRP rods in simply supported beams such as El-Mogy et al. (2011), Alsayed and Alhozaimy (1999), Vijay and Rao (2001), Alves et al. (2010), LaftahAbbas et al. (2018) and Chen et al. (2012). While, few investigations have been studied the behavior of continuous beams provided with FRP bars such as Bencardino et al. (2016), Dundar et al. (2015) and El-Mogy et al. (2010). Previous research has dealt with the redistribute of moment in samples provided by FRP rods and the flexural behavior of these type of beams.

In this research, a 3-D sample was created and used to analyze the general demeanor of continuous concrete beams reinforced by carbon polymeric fiber rods.

Finite element simulation: The analysis program adopted in this study is ANSYS which is widely used for the analysis of engineering structures with excellent efficiency depend on the previous experimental results. This program contains a library of many elements that can simulate and represent the real materials used in laboratory testing. The desired element is selected based on the materials involved in the composition of the real structural component that has been laboratory tested and is theoretically analyzed using the program. By relying on previous research, numerical studies and sufficient experience in knowing the extent to which the desired engineering representation can be achieved the (SOLID65) was selected to represent the concrete component. The element consists of eight nodes and has the freedom to move in three directions for each node, Geometric shape, coordinate system and location of the nodes for this element are shown in Fig. 1.

In addition, LINK180 element was chosen to simulate the ordinary reinforcing steel and the fibers polymer rods. LINK 180 can be used in the representation of trusses and curved wires, springs, etc. This element has the freedom

Corresponding Author: Qusay W. Ahmed, College of Engineering, University of Diyala, Baqabah, Iraq qusaywahmed20@gmail.com 

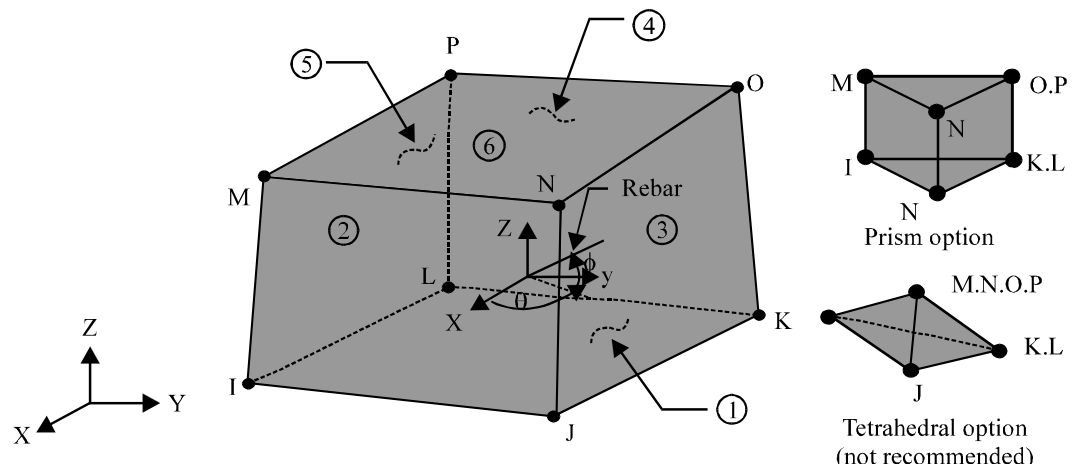

Tetrahedral option (not recommended)

Fig. 1: SOLID65 in ANSYS
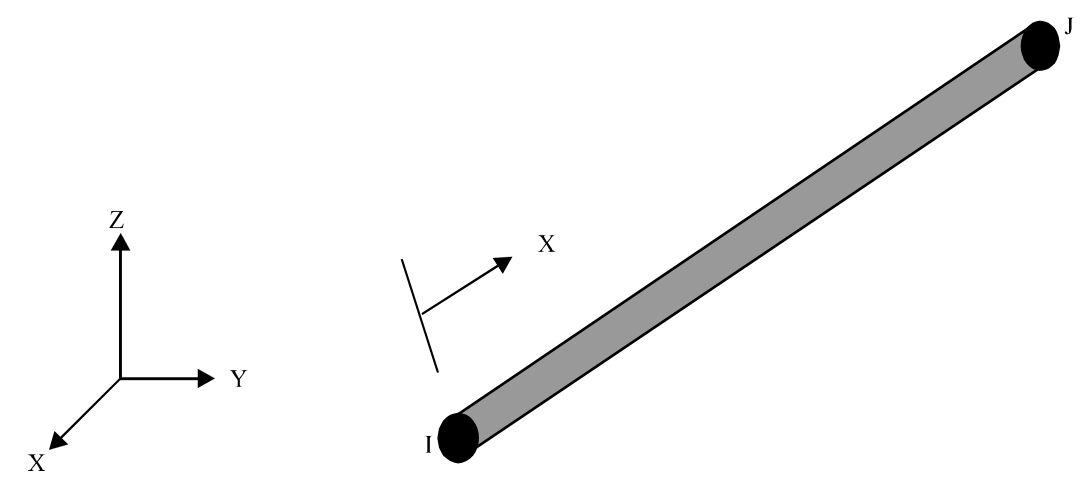

Fig. 2: LINK180 geometry

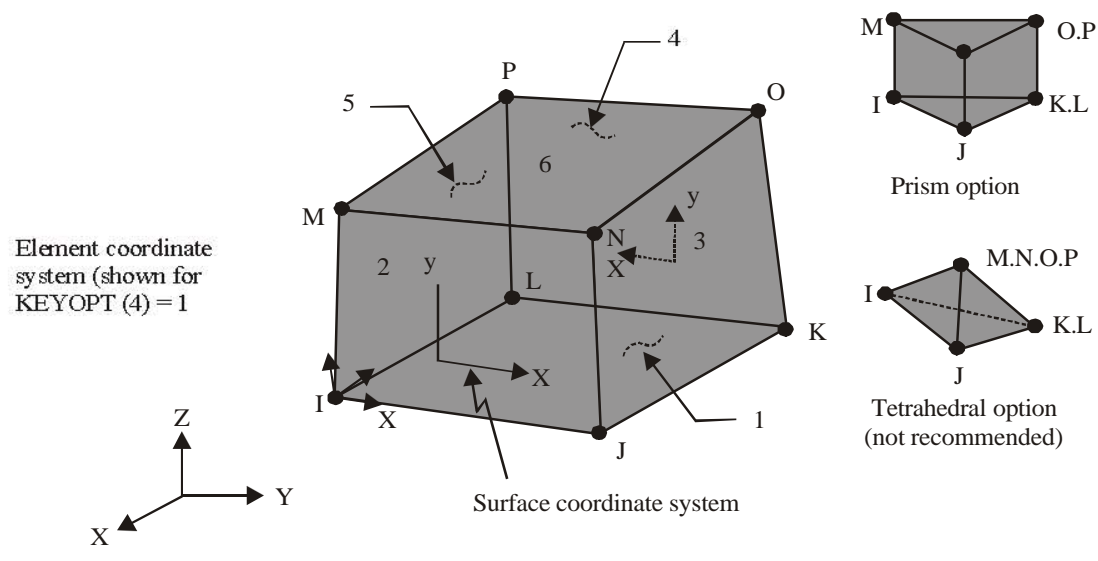

Fig. 3: SOLID45 geometry

to move in 3 directions at each node. The bending in this type of element is not taken into consideration. Geometric shape, coordinate system and location of the nodes for this element are shown in Fig. 2.

To avoid concentration of stresses in the area under loads, bearing plates are used. This will contribute to the redistribution of concentrated stresses in this region and thus the partial failure of the structure will not occur the element (SOLD45) was used for simulate the plates. This element consists of eight nodes and has the freedom to move in three directions are shown in Fig. 3.

\section{MATERIALS AND METHODS}

Material modeling: For the theoretical analysis of the continuous concrete beams provided by FP rods in the ANSYS program requires engineering representation compatible with the practical model and to be analyzed. This is done by representing the main materials that make up the concrete beam which includes: concrete, FRP rods and bearing plates elements that are demonstrate in sequel. These components are represented by a three-dimensional model that is created through 


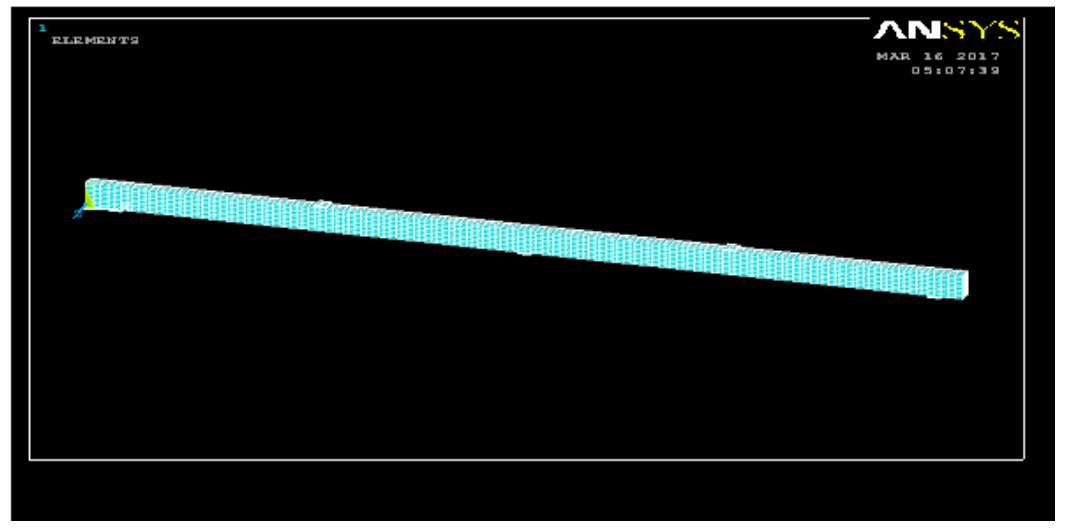

Fig. 4: Modeling of continuous beam reinforced with FRP in ANSYS

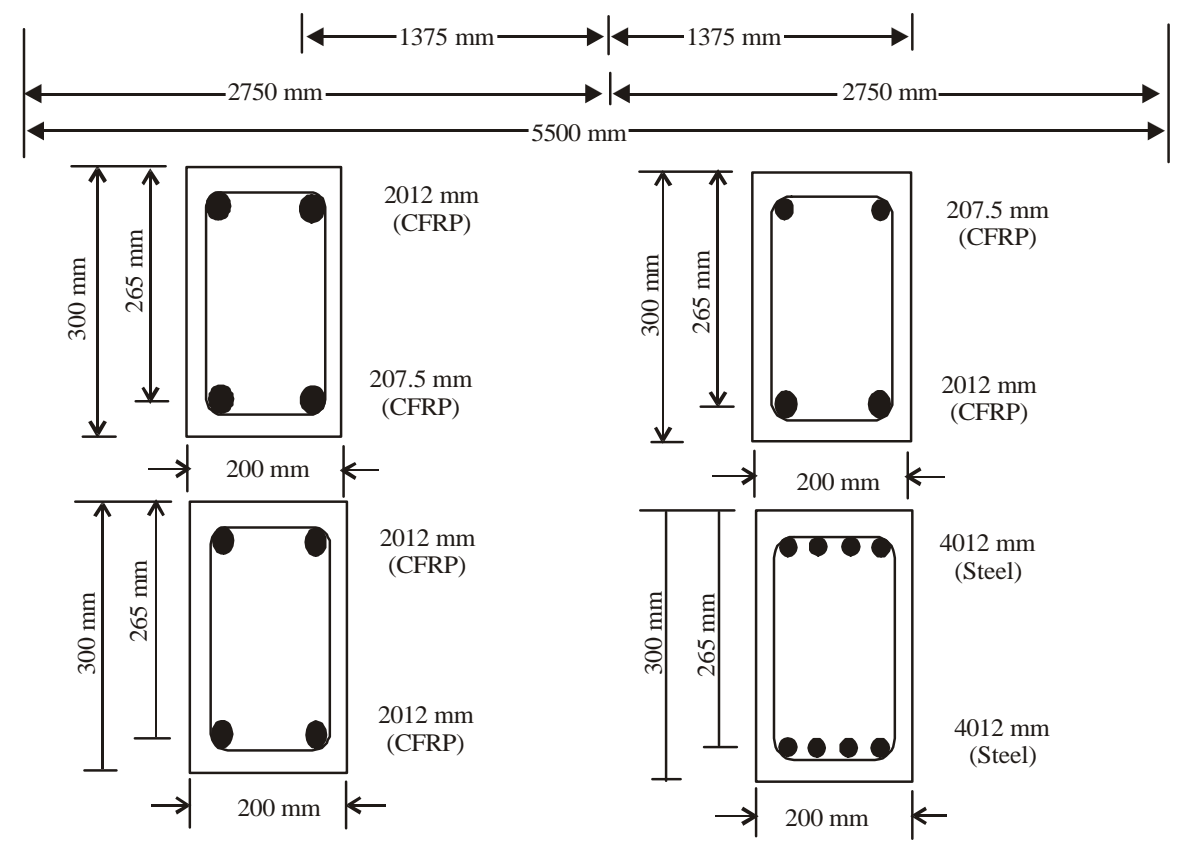

Fig. 5: Details of experimental beams (Ashour and Habeeb, 2015)

the program used in this study as shown in Fig. 4. The equation of Desayi and Krishnan (1964) is used to represent of stress-strain relation for concrete while the stress-strain relationship of FRP reinforcement is used as (Almassri et al., 2016).

Numerical model: After completion of the engineering representation of models and the applying of loads and the restriction procedure the models are examined theoretically using the engineering analysis program (ANSYS). To achieve the analysis, four practical models were selected which were examined by laboratory by Ashour and Habeeb (2015). The first three models
$\mathrm{CCl}$-CC3 were provided by Carbon FRP rods and the forth Model SC4 is reinforced by steel bars. The purpose of this analysis is to study and research the behavior of this type of beams provided by carbon fiber polymer rods and compare them with the beams provided by conventional steel bars, through a general numerical study including The effect of CFRP rods on the maximum resistance. For the purpose of accuracy and reliability of the program in the analysis of this type of concrete beams, the theoretical results were compared with the practical results.

The cross section for all models is $0.3 \times 0.2 \mathrm{~m}$ depth and width. Each beam has two spans with $(2750 \mathrm{~mm})$ for each of them as shown in Fig. 5. All reinforced concrete 
Table 1: Properties and details of laboratory samples

\begin{tabular}{lclclcr}
\hline & & Upper rein & & Bottom rein & & \\
Samples & Span $(\mathrm{mm})$ & Number & Diameter $(\mathrm{mm})$ & Number & Diameter (mm) & strength (MPa) \\
\hline CC1 & 5500 & 2CFRP & 12 & 2CFRP & 7.5 & 23.6 \\
CC2 & 5500 & 2CFRP & 7.5 & 2CFRP & 12 & 27.2 \\
CC3 & 5500 & 2CFRP & 12 & 2CFRP & 12 & 28.0 \\
SC4 & 5500 & 4Steel & 12 & 4Steel & 12 & 26.3 \\
\hline
\end{tabular}

Table 2: Properties of reinforced rods

\begin{tabular}{lcccc} 
Type of rods & Diameter $(\mathrm{mm})$ & Modulus of elasticity (GPa) & Maximum strength (MPa) & Yield strength (MPa) \\
CFRP & 7.50 & 200.00 & 2000 & N/A \\
CFRP & 12.00 & 200.00 & 1061 & N/A \\
Steel (stirrup) & 8.00 & 206.80 & 611.6 & 525.5 \\
Steel & 12.00 & 200.00 & 594.4 & 510.8 \\
\hline
\end{tabular}

models with carbon fiber rods were provided in a three contingents to achieve the reinforcement installation at the bottom and top layers. The groups were: two rods of $12.0 \mathrm{~mm}$ diameter at the upper and two rods of $7.5 \mathrm{~mm}$ diameter $\mathrm{mm}$ at the bottom in sample $\mathrm{CCl}, 2$ rods of $7.50 \mathrm{~mm}$ diameter at the upper and 2 rods of $12.0 \mathrm{~mm}$ diameter at the lower in sample $\mathrm{CC} 2$ and 2 rods of $12 \mathrm{~mm}$ diameter $\mathrm{mm}$ at the upper layer and the bottom layer in sample CC3 as in Fig. 5 and Table 1 and 2. The ordinary reinforcing steel (four rods of $12.0 \mathrm{~mm}$ diameter) $4 \phi 12 \mathrm{~mm}$ of the sample SC4 was chosen.

\section{RESULTS AND DISCUSSION}

Curve of load-midspan deflection: The curves of applied load and deflection at the middle of the span for all models that were theoretically analyzed using the ANSYS program were compared with the laboratory results obtained as illustrated in Fig. 6-9. Generally, we notice that the curves of theoretical applied load and deflection correspond to a large extent with the practical results and during the entire behavior of the model.

Ultimate failure loads: Table 3 illustrated the comparison of the maximum load failure of the examined beams $(\mathrm{Pu})_{\operatorname{EXP}}$ and the final load of the samples by the theoretical analysis program, $(\mathrm{Pu})_{\mathrm{FEM}}$. The final loads of the theoretical analysis model were monitored for the last supplied loading steps and before the diverging because cracking and high deflection.

The results of the theoretical models at the maximum load were as follows are $(77.220,93.950,90.30$ and $166.150 \mathrm{kN}$ ) for beams (CC1-CC3) and (SC4), respectively.

With comparison with the results of the practical examination offer $(2.6,1.36,3.53$ and $2.19 \%)$ increase in ultimate loads for the beams (CC1-CC3) and (SC4), respectively.

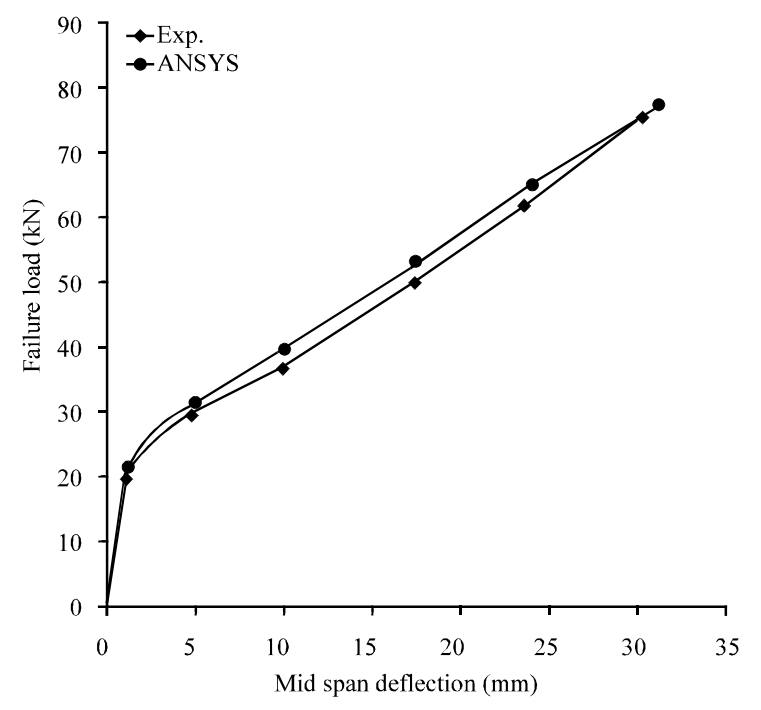

Fig. 6: Curve of applied load and mid span deflection for $\mathrm{CC} 1$

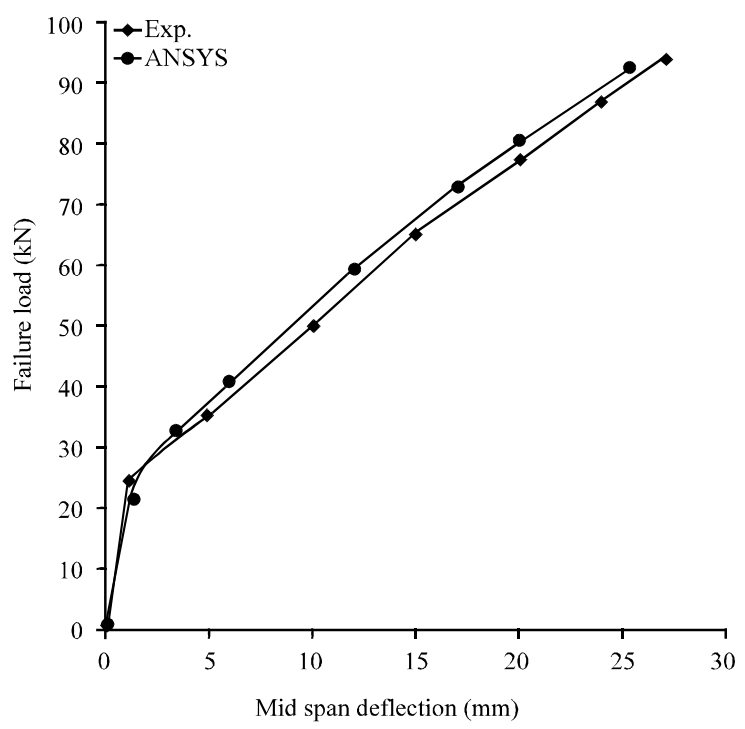

Fig. 7: Curve of applied load and mid span deflection for $\mathrm{CC} 2$ 
Table 3: Comparison of ultimate applied loads of theoretical and experimental results

\begin{tabular}{lccc}
\hline & Maximum load $(\mathrm{kN})$ & & \\
Beams & - & & \\
\hline $\mathrm{CC} 1$ & $(\mathrm{Pu})_{\mathrm{EXP}}$ & $(\mathrm{Pu})_{\mathrm{FEM}}$ & $(\mathrm{Pu}) \mathrm{FEM} /(\mathrm{Pu}) \mathrm{EXP}$ \\
$\mathrm{CC} 2$ & 75.25 & 77.22 & 1.026 \\
$\mathrm{CC} 3$ & 93.95 & 92.67 & 0.986 \\
$\mathrm{SC} 4$ & 90.30 & 87.11 & 0.964 \\
\hline
\end{tabular}

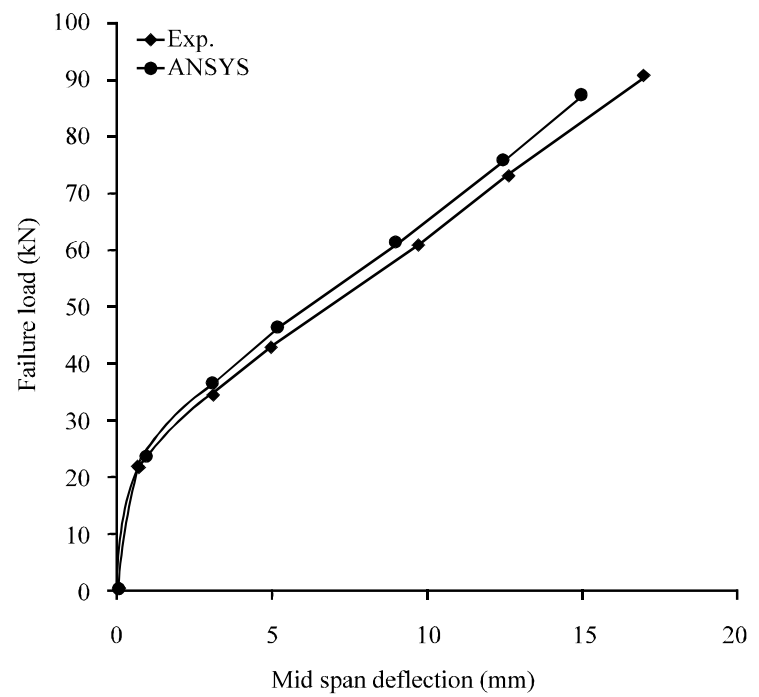

Fig. 8: Curve of applied load and mid span deflection for $\mathrm{CC} 3$

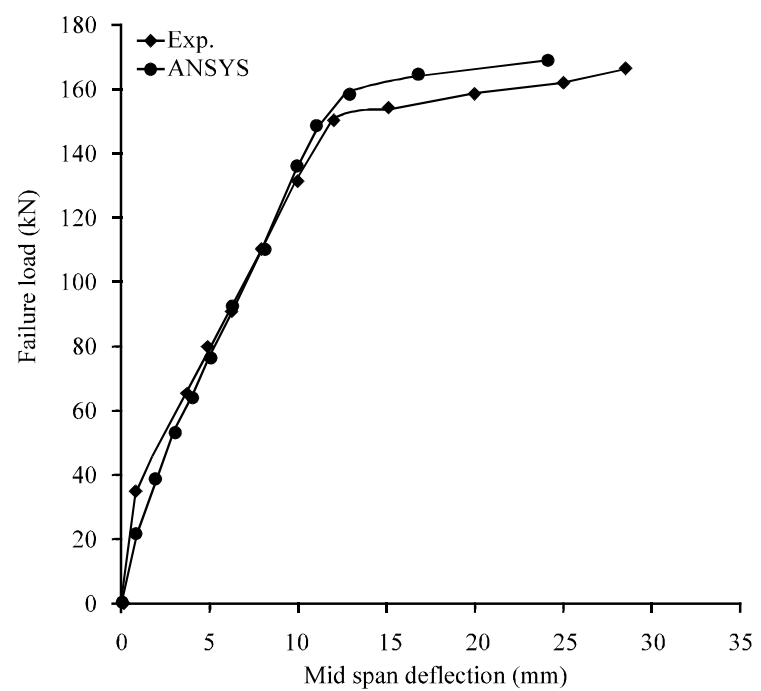

Fig. 9: Curve of applied load and mid span deflection for CS4

Table 3 showing that the maximal load obtained theoretically by analysis program corresponds to a large measure with equivalent practical results.

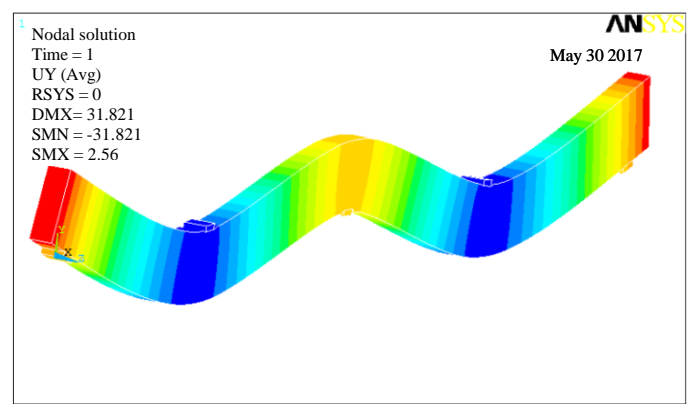

Fig. 10: Deflected mode for sample $\mathrm{CCl}$ at load $=75.25 \mathrm{kN}$

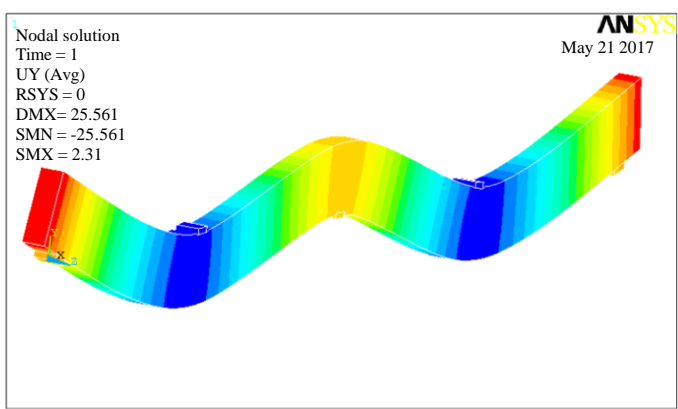

Fig. 11: Deflected mode for sample CC2 at load $=93.95 \mathrm{kN}$

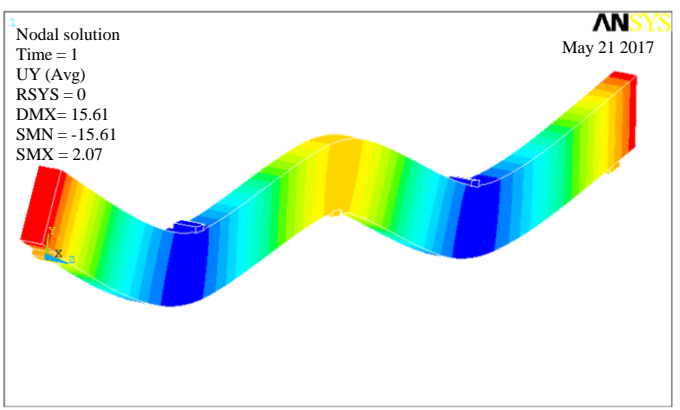

Fig. 12: Deflected mode for sample CC3 at load $=90.3 \mathrm{kN}$

Deflected shape: The deflections (vertical displacement) measured at the center of the middle at the center in the lower face of the sample in y-direction (Uy) and deflected mode output of the applied external loads for all models are shown in Fig. 10-13. 


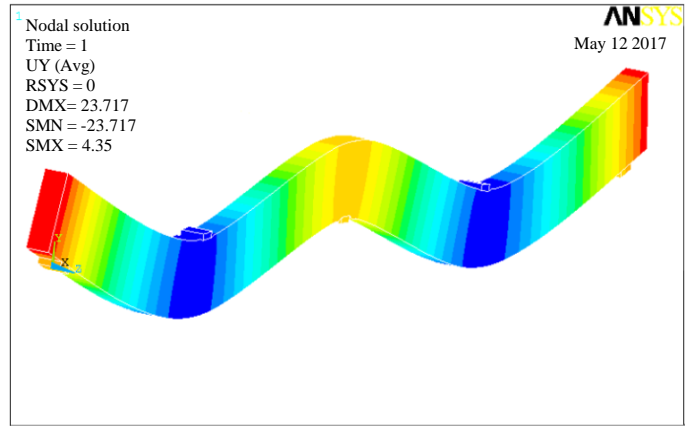

Fig. 13: Deflected mode for sample SC4 at load = $166.15 \mathrm{kN}$

\section{CONCLUSION}

The analysis of all the selected models was adopted using the method of finite elements using the computer program ANSYS (Version 12.0). A 3-D sample was created and analyzed for research and study of general behavior of continuous beams provided by polymeric carbon fiber rods. The theoretical analysis model in the current research can model and simulate the practical continuous concrete beams. The theoretical test using the program ensures a study of the behavior of the deflection and the maximum loads show reliable results and are very consistent with the results of the practical analysis. From this theoretical study, the researcher concluded that the main factor of increasing load and carrying capacity is achieved by increasing CFRP rods in the lower layer of the concrete beam but for upper layer the increasing CFRP reinforcement has inconsiderable action on maximum load capacity and deflection.

\section{REFERENCES}

Almassri, B., F. Al Mahmoud and R. Francois, 2016. Behaviour of corroded reinforced concrete beams repaired with NSM CFRP rods, experimental and finite element study. Comp. Part B Eng., 92: 477-488.

Alsayed, S.H. and A.M. Alhozaimy, 1999. Ductility of concrete beams reinforced with FRP bars and steel fibers. J. Compos. Mater., 33: 1792-1806.
Alves, J., A. El-Ragaby and E. El-Salakawy, 2010. Durability of GFRP bar's bond to concrete under different loading and environmental conditions. J. Comp. Constr., 15: 249-262.

Ashour, A.F. and M.N. Habeeb, 2015. Continuous concrete beams reinforced with CFRP bars. Proc. Inst. Civil En. Struct. Build., 161: 349-357.

Bencardino, F., A. Condello and L. Ombres, 2016. Numerical and analytical modeling of concrete beams with steel, FRP and hybrid FRP-steel reinforcements. Comp. Structur., 140: 53-65.

Chen, G.M., J.F. Chen and J.G. Teng, 2012. On the finite element modelling of $\mathrm{RC}$ beams shear-strengthened with FRP. Constr. Build. Mater., 32: 13-26.

Desayi, P. and S. Krishnan, 1964. Equation for the stress-strain curve of concrete. J. Proc., 61: 345-350.

Dundar, C., A.K. Tanrikulu and R.J. Frosch, 2015. Prediction of load-deflection behavior of multi-span FRP and steel reinforced concrete beams. Compos. Structur., 132: 680-693.

El-Mogy, M., A. El-Ragaby and E. El-Salakawy, 2010. Flexural behavior of continuous FRP-reinforced concrete beams. J. Comp. Constr., 14: 669-680.

El-Mogy, M., A. El-Ragaby and E. El-Salakawy, 2011. Behavior of Continuous Concrete Beams Reinforced with FRP Bars. Proceedings of the 5th International Conference on FRP Composites in Civil Engineering (CICE 2010), September 27-29, 2010, Springer, Beijing, China, ISBN:978-3-642-17486-5, pp: 283-286.

Hollaway, L.C., 2011. Key Issues in the Use of Fibre Reinforced Polymer (FRP) Composites in the Rehabilitation and Retrofitting of Concrete Structures. In: Service Life Estimation and Extension of Civil Engineering Structures, Karbhari, V.M. and L.S. Lee (Eds.). Woodhead Publishing, Sawston, UK., pp: 3-74.

LaftahAbbas, A., Q.W. Ahmed and W.D. Salman, 2018. Nonlinear behavior of reinforced concrete deep beams reinforced with internal fiber-reinforced polymer. Intl. J. Civil Eng. Technol., 9: 2811-2825.

Vijay, P.V. and V.S.H.G. Rao, 2001. Bending behavior and deformability of glass fiber-reinforced polymer reinforced concrete members. ACI Struct. J., 98: 834-842. 